\title{
Gas Solubility of Carbon Dioxide in Poly(lactic acid) at High Pressures: Thermal Treatment Effect
}

\author{
N. S. OLIVEIRA, ${ }^{1}$ J. DORGAN, ${ }^{2}$ J. A. P. COUTINHO, ${ }^{1}$ A. FERREIRA, ${ }^{3}$ J. L. DARIDON, ${ }^{4}$ I. M. MARRUCHO $^{1}$ \\ ${ }^{1}$ CICECO, Departamento de Química, Universidade de Aveiro, 3810-193 Aveiro, Portugal \\ ${ }^{2}$ Colorado School of Mines, Golden, Colorado 80401 \\ ${ }^{3}$ CICECO, ESTGA, Ap. 473, 3754-909 Águeda, Portugal \\ ${ }^{4}$ Laboratoire Haute Pression, CURS, Université de Pau, Avenue de I'Université, 64000 Pau, France
}

Received 3 January 2006; revised 2 June 2006; accepted 22 August 2006

DOI: 10.1002 / polb.20969

Published online in Wiley InterScience (www.interscience.wiley.com).

\begin{abstract}
The sorption of carbon dioxide in glassy Poly(lactic acid) (PLA) films was studied by quartz crystal microbalance (QCM) at high pressures. Two thermal treatments, melted and quenched, were performed in PLA with two different $L: D$ contents, 80:20 and 98:2, films and compared with a third thermal protocol, annealed, and used in a previous work. The results obtained show that for pressures higher than $2 \mathrm{MPa}$, the carbon dioxide solubility is larger in PLA 80:20 than in PLA 98:2, indicating that the $L: D$ plays a dominant role on this property. The thermal treatments only affect the gas solubility in PLA 98:2. Sorption isotherms at temperatures 303, 313, and $323 \mathrm{~K}$, below the glass transition temperature of the polymer, and pressures up to $5 \mathrm{MPa}$ were measured and analyzed with three different models, the dual-mode sorption model, the Flory-Huggins equation, and a modified dual-mode sorption model where the Henry's law term was substituted by the Flory-Huggins equation. This last model performs especially well for $\mathrm{CO}_{2}$ in PLA 80:20, due to the convex upward curvature of the solubility isotherms for that system. (2007 Wiley Periodicals, Inc. J Polym Sci Part B: Polym Phys 45: 616-625, 2007
\end{abstract}

Keywords: biodegradable polymer; high pressure; poly(lactic acid) (PLA); quartz crystal microbalance; sorption; thermal treatment

\section{INTRODUCTION}

The sorption of gases and vapors in glassy polymers is of fundamental interest in the development of barrier membranes, foaming processes, impregnation of polymers with additives, controlled release of chemicals and microsensor materials. The experimental methods used to measure gas solubility in polymers can be divided

Correspondence to: I. M. Marrucho (E-mail: imarrucho@ dq.ua.pt)

Journal of Polymer Science: Part B: Polymer Physics, Vol. 45, 616-625 (2007) @2007 Wiley Periodicals, Inc.

616 into 4 main classes: barometric or pressuredecay methods, in which the quantity of gas sorbed by a polymer is obtained from the difference between the amount of gas initially contacted with the polymer and the amount remaining in the gas phase at equilibrium; gravimetric methods, in which the quantity of gas is measured; flow methods, such as inverse gas chromatography; and oscillating techniques, in which the increase of mass is deduced from the resonant characteristics of a vibrating support. Barometric and gravimetric methods are been the most extensively used due to their high sensitivity and precision. However, they are time 
consuming, since hours or even days are required for the equilibration to be achieved.

A growing body of literature ${ }^{1-7}$ has been proposing quartz crystal microbalances (QCM) as a valuable tool in the assessment of sorption model parameters of gases and vapors for rubbery polymers and more recently for glassy polymers at moderate to high pressures. This method has been used since 1975, when Bonner and Cheng ${ }^{8}$ introduced it to measure nitrogen sorption in glassy low-density polyethylene. This method has the advantage of being highly sensitive, detecting mass uptakes on the order of nanograms, while a short equilibration time is required, on the order to 15-30 min depending on the systems and the conditions. Wang et al. ${ }^{1}$ measured solubility of carbon dioxide in rubbery poly(vinyl acetate), PVAc, and poly(butylmethacrylate), PBMA, and Aubert ${ }^{3}$ explored the $\mathrm{CO}_{2}$ sorption in a wide variety of both rubbery and glassy polymers. Miura et al. ${ }^{2}$ studied the effect of different deposition techniques in the sorption of $\mathrm{CO}_{2}$ in polystyrene. Boudouris et al. ${ }^{4}$ measured solubility of HCFC-22 and HFC-152a in glassy PS and PMMA. More recently, Zhang et al. $^{5-7}$ fully explored the reliability of the application of this technique to sorption of carbon dioxide in glassy poly(ethylene terephatalate) (PET) and in plasma polymerized methyl methacrylate (ppMMA) at high pressures as well as methanol vapors in ppMMA. The FloryHuggins equation and the dual mode sorption models were used to derive sorption parameters for the studied systems.

Two factors influence the sorption of small molecules in glassy polymers: the nonequilibrium excess free volume and the crystallinity. ${ }^{9}$ The presence of crystallites influences the transport properties since not only they create a tortuous path for the penetrant by acting as impermeable barriers, but they may also restrict the chain mobility in the amorphous phase by acting as virtual crosslinkers and thus reducing the available volume for penetrant sorption. ${ }^{10,11}$ It is assumed that for the penetrant to dissolve in the crystal, it would need a disruption of the crystallites and usually there is not enough energy from sorption to accomplish this process. This is corroborated by experimental data ${ }^{9}$ where extrapolation of solubility data to zero percent amorphous phase yields null solubility.

The nonequilibrium excess free volume, or simply the excess free volume, reflects the nonequilibrium structure of a glassy amorphous polymer, which results from passing the polymer from the rubbery state into the glassy state. Physical treatments, such as temperature treatment and pressure conditioning, were found to effectively control the excess free volume. ${ }^{12}$ It is well known that the structure of glassy polymers depends upon their thermal history, that is, the local structure of a glassy material is expected to change according to various conditions of the glass formation. Sub- $T_{\mathrm{g}}$ annealing, thermal quenching, $\mathrm{CO}_{2}$, or He pressure conditioning are the most used physical treatments applied to glassy polymers in general to study a specific system for a specific application. Several authors used the QCM to study the influence of the thermal history of the polymer in the gas sorption. Zhang et al. ${ }^{6,7}$ and Russell and Weinkauf ${ }^{13}$ compared two different coating methods, polymer solution casting and plasma polymerization of monomers. Both authors found out that effect of the thermal treatment is significantly smaller in the plasma polymerized than that in the cast film. Zhang et al. ${ }^{6}$ performed a more detailed analysis of the effect of different thermal conditionings on sorption results and concluded that the slower the thermal conditioning is applied the more complete relaxation of the cast glassy polymer film, diminishing the excess free volume available for sorption.

The objective of this work is to study the influence of the thermal treatment on the sorption of carbon dioxide in poly(lactic acid) (PLA) films at high pressures. For that purpose a high pressure QCM is going to be used, since this technique presents a high sensitivity and high accuracy combined with low equilibration times. The carbon dioxide solubility in PLA films with two different $L: D$ contents, 80:20 and 98:2, subjected to three different thermal treatments, melting and quenching, and annealing, are compared and discussed.

\section{MATERIALS AND CHARACTERIZATION METHODS}

The biodegradable polymer, poly(lactic acid) (PLA), was produced by Cargill-Dow Polymers with two different $L: D$ contents, 80:20 and 98:2. The characteristics of PLA were given by suppliers and they are reported in Table 1. Carbon dioxide was purchased from Messer with a purity of $99.998 \%$. Dichloromethane was obtained from Riedel-deHaan with analytical reagent 
Table 1. Principal Characteristics of the Polymers Used in This Work

\begin{tabular}{lcc}
\hline \multicolumn{1}{c}{ Properties } & PLA 80:20 & PLA 98:2 \\
\hline LL (\%) & 80 & 98 \\
$\mathrm{DD}(\%)$ & 20 & 2 \\
$\mathrm{DL}(\%)$ & 0 & 0 \\
$T_{\mathrm{g}}(\mathrm{K})$ & 324.6 & 332.7 \\
Density $\left(\mathrm{g} \mathrm{cm}^{-3}\right)$ & $1.2639^{\mathrm{a}}$ & $\mathrm{NA}$ \\
$M_{\mathrm{w}}(\mathrm{Da})$ & 102,800 & 87,131 \\
Polydispersity & 1.46 & $\mathrm{NA}$ \\
\hline \multicolumn{2}{c}{ a Measured value at $293.2 \mathrm{~K}$, density $(T)=1.2835$} \\
$\mathrm{e}^{-0.0007701 T /{ }^{\circ} \mathrm{C}}$.
\end{tabular}

grade. Solvent and gases were used with no further purification. The quartz crystals were of $9 \mathrm{MHz}$ base frequency, with golden electrodes of $5 \mathrm{~mm}$ and were supplied by ICM (USA).

A Differential scanning calorimeter, DSC-50/ DTA-50 from Shimadzu, was used to measure the glass transition temperature and the melting temperature of PLA. The crystallinity of the polymer films was estimated from the DSC results and X-Ray diffraction tests were performed in a Philips X'Pert automatic X-ray diffractometer with $2 \theta$ from $5^{\circ}$ to $33^{\circ}$.

\section{EXPERIMENTAL}

A simplified scheme of the high pressure QCM used to measure the sorption isotherms of carbon dioxide in PLA between 303.2 and $323.2 \mathrm{~K}$ and up to $5 \mathrm{MPa}$ is presented in Figure 1. This apparatus was built to operate in the temperature range from 303.2 to $373.2 \mathrm{~K}$ and pressures from 0.1 to $35 \mathrm{MPa}$. Since it was described in detail by Oliveira et al., ${ }^{14}$ only a brief description is given here for sake of completeness.

The apparatus consists mainly of a high pressure cell, made of nonmagnetic stainless steel, which is placed inside a temperature-controlled air oven that controls and maintains the desired temperature within $\pm 0.1 \mathrm{~K}$. Two AT-cut quartz $9 \mathrm{MHz}$ crystals, the reference and the working crystal, are installed inside the solubility cell. The crystals are connected to two oscillators installed outside the solubility cell. The oscillators are powered by a stabilized potential of $5.0 \mathrm{~V}$ and the resonant frequencies around the nominal frequency of $9.0 \mathrm{MHz}$ were measured for both quartz crystals using a 10 digits frequency counter (Agilent 53131A) connected to a computer for recording. The temperature was measured through a platinum probe (Pt100) placed inside the cell at $1 \mathrm{~cm}$ of both quartz crystals and connected to an Agilent 34401A multimeter. The solubility cell is connected to a pressure sensor pressure transducer from Setra, model 204 , with a precision of $0.005 \mathrm{MPa}$.

The working and reference quartz crystal are outgassed for at least $2 \mathrm{~h}$. The gas is then introduced in the system and allowed to equilibrate with the polymer sample coated in the working crystal. The pressure transducer and the multimeter for temperature recording are connected to a personal computer for real time data acquisition and recording.

The $9 \mathrm{MHz}$ crystals were thoroughly cleaned with dichloromethane until the base frequency became constant (less than $1 \mathrm{~Hz}$ in $10 \mathrm{~min}$ ). A thin polymer coating is prepared by dropping a dilute solution of PLA in dichloromethane, about $0.5 \%(\mathrm{w} / \mathrm{w})$ on both sides of the quartz crystal electrode surface. The polymer coated on the crystal was prepared by two distinct thermal treatments: melted, introducing the coated crystal in the oven at ambient temperature, heating up to $523.2 \mathrm{~K}$ at $2 \mathrm{~K} \mathrm{~min}^{-1}$ and cooling down to ambient temperature at $10 \mathrm{~K} \mathrm{~min}^{-1}$; quenched, introducing the coated crystal in the oven at ambient temperature, heating up to $523.2 \mathrm{~K}$ at $2 \mathrm{~K}$ $\min ^{-1}$ and rapidly placing it in a chamber at $259 \mathrm{~K}$. The total mass of polymer coated on the quartz crystal can be determined by the difference in the oscillation frequency measured

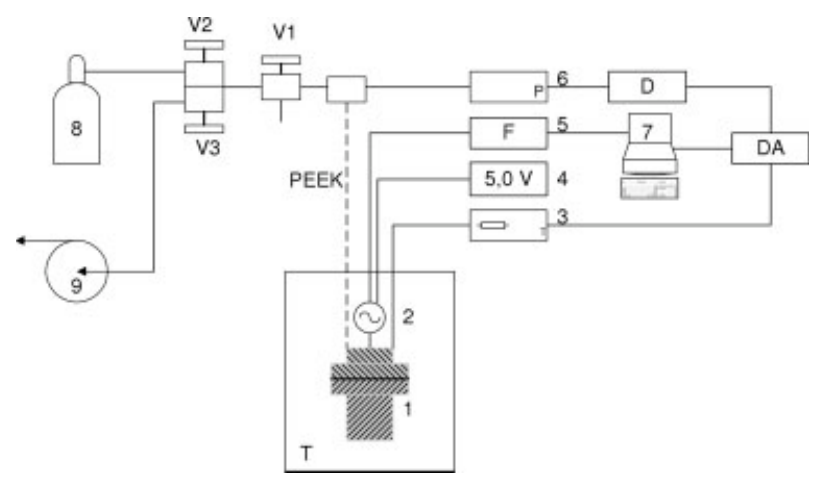

Figure 1. The high-pressure QCM apparatus: 1, solubility cell; 2, oscillator; 3 , multimeter for Pt100; 4, power supply for oscillator; 5 , frequency counter; 6 , pressure transducer; 7 , computer; 8 , gas bottle; 9 , vacuum pump; T, air bath (oven); D, digital display of the pressure transducer; DA, data acquisition system; $\mathrm{V} 1, \mathrm{~V} 2$, and V3 are high pressure valves.

Journal of Polymer Science: Part B: Polymer Physics 
before coating and after the thermal treatment, $\Delta F_{\mathrm{C}}$.

As it was discussed by Oliveira et al., ${ }^{14}$ the gas sorption frequency change in the polymer, $\Delta F_{\mathrm{S}}$, is calculated from the difference of the frequency change due to gas sorption between the reference crystal, $\Delta F_{\mathrm{P}, \mathrm{V}}$, and the measuring crystal coated with polymer, $\Delta F_{\mathrm{E}}$, given by

$$
\Delta F_{\mathrm{S}}=\Delta F_{\mathrm{E}}-\Delta F_{\mathrm{P}, \mathrm{V}}
$$

Assuming that the differences in the properties of the crystals are negligible before and after sorption, the gas solubility in polymer, $C(\mathrm{v} / \mathrm{v})$, is calculated by

$$
C=\frac{\Delta F_{\mathrm{S}} \rho_{\mathrm{pol}}}{\Delta F_{\mathrm{C}} M_{\mathrm{gas}}} 22414
$$

where $\rho_{\text {pol }}$. is the polymer density and $M_{\text {gas }}$ is the gas molecular weight.

\section{MODELING}

\section{Dual-Mode Sorption Model}

The dual-mode sorption model (DMSM) assumes that two types of sorption mechanisms take place simultaneously when a fluid interacts with a glassy polymer: one is described by a Henry's law type, which accounts for the sorption of the solute in the polymer matrix and the other is described by a Langmuir type of sorption, which accounts for the solute molecules adsorbed in microcavities. These two types of sorption are typically assumed to occur in nonequilibrium glassy polymers consisting of two parts, a liquidlike state one, where sorption described by the Henry's law behavior is the dominant mechanism, and an amorphous solid state one, where the Langmuir type of sorption is preferred. The DMSM is described by

$$
C=k_{\mathrm{D}} p+C_{\mathrm{H}}^{\prime} \frac{b p}{1+b p}
$$

where $C$ is the solubility of the gas in the polymer film, $k_{\mathrm{D}}$ is the Henry's law coefficient, $b$ represents the hole affinity parameter, which is a measure of the affinity between the solute molecules and the Langmuir sites, $C_{H}^{\prime}$ is the capacity parameter, characterizing the saturation of these cavities, and $p$ is the pressure. This model has been extensively used to model the gas solubilities in glassy polymers and the obtained results have been reviewed recently. ${ }^{15}$

\section{Flory-Huggins Equation}

The Flory-Huggins equation has been thoroughly described in the literature ${ }^{16-19}$ and widely used to correlate experimental data of solubility of gases in polymers. This model considers that the activity coefficient results from entropic rather than enthalpic effects. The mixture entropy is calculated from the lattice theory, where each molecule occupies a number of sites proportional to its molecular volume. The mixture enthalpy is described by a binary interaction parameter, $\chi_{12}$, which is used to correlate the experimental results. The Flory-Huggins equation can be written as

$$
\ln \left(a_{1}\right)=\ln \left(\phi_{1}\right)+\left(1-\frac{1}{r}\right) \phi_{2}+\chi_{12} \phi_{2}^{2}
$$

$$
r=\frac{v_{2} M_{2}}{v_{1} M_{1}}
$$

$$
\phi_{1}=\frac{v_{1} w_{1}}{v_{1} w_{1}+v_{2} w_{2}} \quad \text { and } \quad \phi_{2}=1-\phi_{1}
$$

where $a_{1}$ is the penetrant activity, $w_{1}$ is the mass fraction of each component $i, r$ is the number of segments in the polymer molecule, $M_{1}$ is molecular weight of penetrant and $M_{2}$ is average molecular weight of polymer. The measured penetrant activity is obtained from

$$
a_{1}=\frac{p}{p^{\text {sat }}} \frac{\varphi_{1}}{\varphi_{1}^{\text {sat } F P}}
$$

where $p$ is system pressure, $p^{\text {sat }}$ is saturation pressure at system temperature, $\phi_{1}$ is fugacity coefficient of penetrant and $\phi_{1}^{\text {sat }}$ is fugacity coefficient at saturation conditions. The fugacity coefficients were calculated using the DDMIX, NIST $^{20}$ software. This software uses an equation of state of modified Benedict-Web-Rubin type with 32 specific terms for $\mathrm{CO}_{2}$. The Poynting factor, $F P$, was calculated considering a linear relation between volume and pressure. At 313 and $323 \mathrm{~K}$, the $\mathrm{CO}_{2}$ vapor pressure is extrapolated from the Antoine equation, since $\mathrm{CO}_{2}$ is supercritical at those conditions. 


\section{Flory-Huggins/Langmuir DMSM}

Since the Flory-Huggins equation does not account the excess free volume, the solubility in glassy polymers cannot be satisfactorily correlated. McDowell ${ }^{9}$ presented a Generalized Sorption Isotherm and used it to describe the sorption of condensable gases in glassy polymers. This model is a combination of Langmuir, $C_{\mathrm{L}}$, and Flory-Huggins isotherms, $C_{\mathrm{FH}}{ }^{9,21-23}$ :

$$
C=C_{\mathrm{FH}}+C_{\mathrm{L}}
$$

The solubility is calculated adjusting three parameters, the Flory-Huggins binary interaction parameter, $\chi_{12}$, the capacity parameter of Langmuir isotherm, $C_{\mathrm{H}}^{\prime}$, and the hole affinity parameter, $b$. The Flory-Huggins solubility term, $C_{\mathrm{FH}}$, is calculated by

$$
C_{\mathrm{FH}}=\frac{w_{1}}{1-w_{1}} \frac{\rho_{\mathrm{pol}} V_{\mathrm{m}}}{M_{\mathrm{g}}}
$$

where $w_{1}$ is the mass fraction calculated similarly as in eq 4 . The Langmuir solubility term, $C_{\mathrm{L}}$, is calculated by

$$
C_{\mathrm{L}}=\frac{C_{\mathrm{H}}^{\prime} b p}{1+b p}
$$

The isotherm represented by this model is concave relative to the pressure axis at low pressures and convex upward at higher penetrant pressures. The latter is associated to plasticization and swelling of the polymer film.

\section{RESULTS}

\section{Film Characterization}

The PLA films were characterized with DSC and X-ray diffraction. All the measurements in DSC were performed up to $473.2 \mathrm{~K}$ at $2 \mathrm{~K} \mathrm{~min}^{-1}$ with 2 complete scans. The first scan is used to measure the crystallization percentage, considering $\Delta H_{\mathrm{m}}=93.6 \mathrm{~J} \mathrm{~g}^{-1}$ for $100 \%$ crystalline L-PLA $^{24}$ and the second scan is used to calculate the glass transition temperature without polymer stress. The DSC results for both PLA 80:20 and 98:2 films with different thermal treatment are presented in Table 2 and compared with the results of Auras et al. ${ }^{25}$ It can be observed that PLA 80:20 is 100\% amorphous for all the thermal treatments performed. The results for PLA
Table 2. DSC Results of the PLA Films with Different $L: D$ Ratio

\begin{tabular}{llcccc}
\hline L:D & Treatment & $T_{\mathrm{g}}(\mathrm{K})$ & $T_{\mathrm{c}}(\mathrm{K})$ & $T_{\mathrm{m}}(\mathrm{K})$ & $\chi \%$ \\
\hline \multirow{2}{*}{$98: 2$} & Annealed & 323.5 & 369.4 & 438.3 & 20 \\
& Melted & 326.0 & 366.8 & 439.5 & 10 \\
& Quenched & 329.2 & 373.7 & 439.3 & 5 \\
80:20 & Annealed & 323.4 & - & - & 0 \\
& Auras et al. & & \\
& & 344.6 & - & 436.6 & 40 \\
\hline
\end{tabular}

$T_{\mathrm{g}}$, glass transition temperature, $T_{\mathrm{c}}$, crystallization temperature, $T_{\mathrm{m}}$, melting temperature, $\chi \%$, percentage crystallinity.

98:2 films show that the crystallization level is about 10 and $5 \%$ for the melted and quenched treatments, respectively. The X-ray diffraction studies carried out at ambient temperature with $2 \theta$ between $5^{\circ}$ and $30^{\circ}, 3 \mathrm{~s}$ per step, and $0.05^{\circ}$ step width corroborate the DSC results.

\section{Solubility Results}

The solubility of carbon dioxide in PLA with $L: D$ content of 80:20 and 98:2 was measured at 303, 313 , and $323 \mathrm{~K}$ up to $5 \mathrm{MPa}$ with the two thermal treatments mentioned previously. PLA 80:20 is completely amorphous, does not crystallize, but PLA 98:2 is semicrystalline with about 5 and $10 \%$ of crystallinity when the quenching and the melting treatments are used, respectively. Taking this fact into account the values of the volume fraction of amorphous polymer were corrected and also the respective solubilities, considering that the crystalline regions do not accommodate any carbon dioxide.

Figure 2(a,b) present the solubility isotherms for carbon dioxide in melted and quenched PLA $80: 20$, respectively. It was only possible to measure the solubility in PLA 80:20 up to $4 \mathrm{MPa}$, since for higher pressures the crystal stops vibrating. This fact is directly related to the amount of polymer deposited on the crystal, which was larger in the PLA 80:20 than in PLA 98:2. The isotherms obtained for carbon dioxide PLA 98:2 with the two thermal protocols referred earlier show a similar behavior as for the PLA 80:20 systems. A point to be noticed is the convex shape of the isotherms for PLA 80:20 above $1 \mathrm{MPa}$, while they show a linear behavior for PLA 98:2. This shape is characteristic of polymer swelling. A possible explanation for this behavior is that the presence of crystallites in 

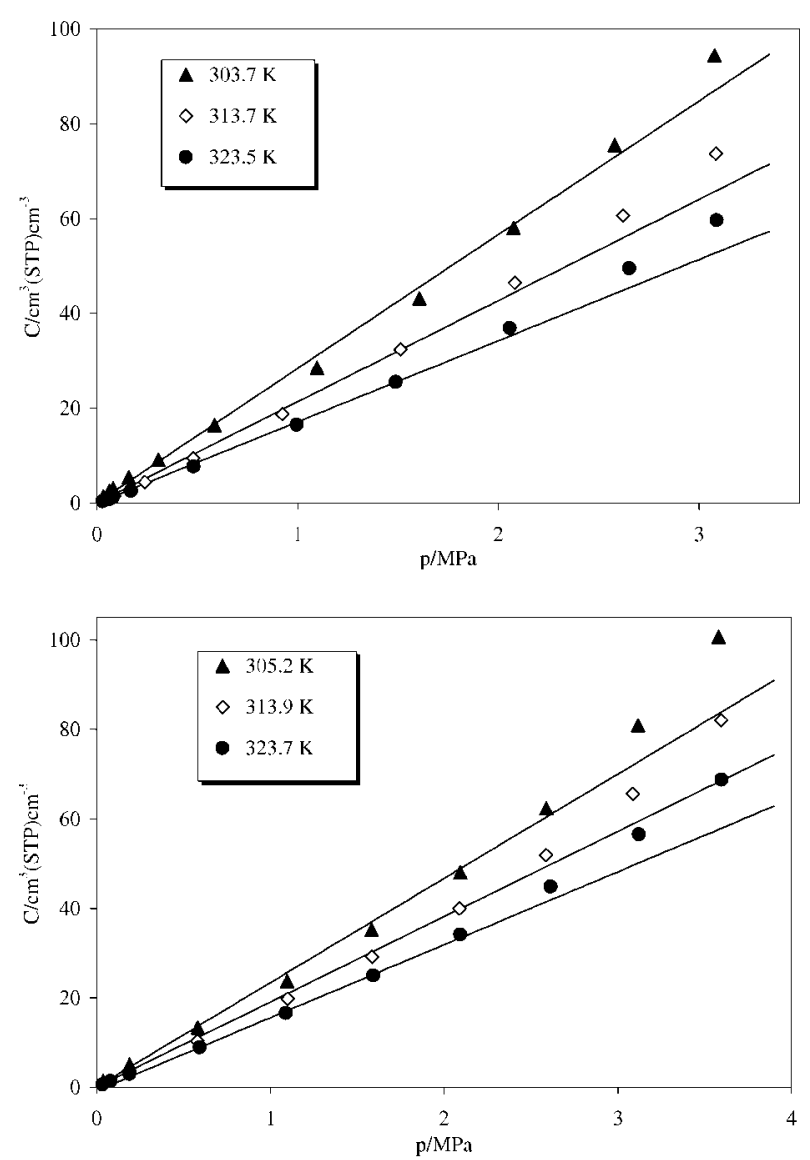

Figure 2. Solubility results of carbon dioxide in PLA 80:20 (a) melted and (b) quenched. Solid lines are calculated using DMSM.

PLA 98:2 restrict the chain mobility in the amorphous phase, acting as virtual crosslinks, thus reducing the volume that can be used for the penetrant to make a diffusional jump and also avoiding the swelling, which takes place in PLA 80:20.

Comparing the two thermal treatments for PLA 80:20, $\mathrm{CO}_{2}$ solubility is about $20 \%$ larger in melted than in quenched PLA 80:20 at $303 \mathrm{~K}$ and it becomes almost the same at the lowest temperature, $323 \mathrm{~K}$. In the case of PLA 98:2, the carbon dioxide solubility is about the same for the melted and the quenched films for all the studied temperatures, indicating that these two thermal treatments do not significantly influence the solubility.

In Figure 3 the results obtained in this work were compared with the results from a previous work for PLA 80:20 and 98:2 with a different thermal treatment, annealing. ${ }^{26}$ The annealing treatment consists on placing the polymer film in an oven at $336.2 \mathrm{~K}$, slightly above the glassy transition temperature, for 2 days, cooled at ambient temperature for 1 day, and placed again in the oven at $336.2 \mathrm{~K}$ for 1 day more. This thermal treatment yields a film of PLA 98:2 with around $20 \%$ of crystallinity, as stated in Table 2 . The most striking fact is the large increase in carbon dioxide solubility in PLA 98:2 annealed compared with the other two thermal treatments. The annealing treatment increases $\mathrm{CO}_{2}$ solubility in PLA 98:2 $\times 30 \%$, on average for the three studied temperatures. On the other hand, the annealing treatment does not seem to have much effect on the carbon dioxide solubility in PLA 80:20. Overall, it can be observed that the carbon dioxide solubility is larger in PLA 80:20 than in PLA 98:2, especially for pressures above $3 \mathrm{MPa}$, probably due to the swelling of PLA $80: 20$.

\section{Modeling Solubility Results}

The DMSM was used to model the solubility of carbon dioxide in PLA. The continuous lines in Figure 2(a,b) represent the correlation with DMSM and the parameters are listed in Table 3. This model correlates very well the results of solubility of carbon dioxide in annealed, melted, and quenched PLA 98:2, with an overall AAD of 1.7, 2.7, and 2.9\%, respectively. In PLA 80:20, the convex upward behavior above $1 \mathrm{MPa}$ determines the weak correlation of the experimental

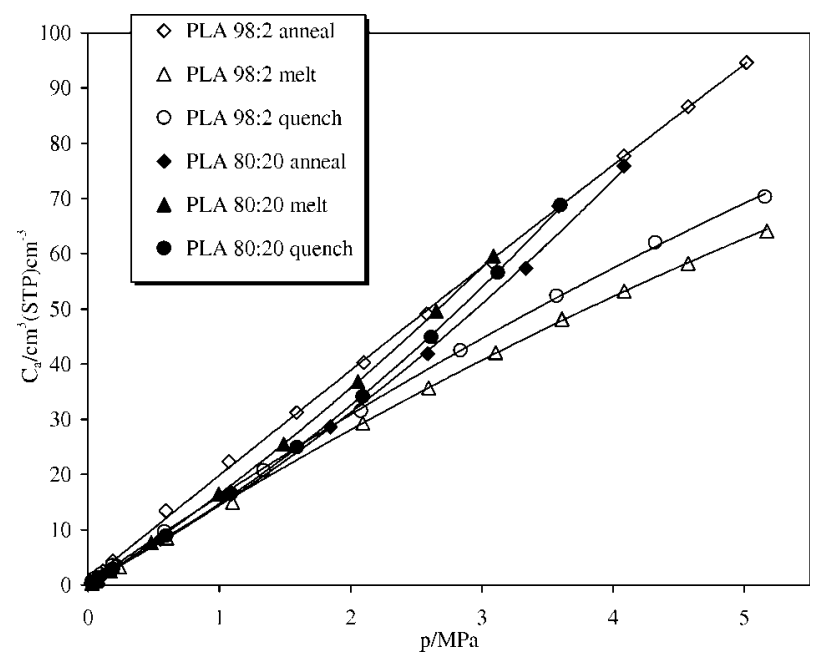

Figure 3. Solubility results for carbon dioxide in PLA 80:20 and PLA 98:2 with the 3 thermal treatments at $323 \mathrm{~K}$. 
Table 3. Dual-Mode Sorption Model Parameters for the Studied Systems and Respective Average Absolute Deviation in Percentage (AAD\%)

\begin{tabular}{|c|c|c|c|c|c|c|}
\hline & $T(\mathrm{~K})$ & $\begin{array}{c}k_{\mathrm{D}}\left(\mathrm{cm}^{3}(\mathrm{STP})\right. \\
\left.\mathrm{cm}^{-3} \mathrm{bar}^{-1}\right)\end{array}$ & $\begin{array}{c}C_{\mathrm{H}}^{\prime} \\
\left(\mathrm{cm}^{3}(\mathrm{STP}) \mathrm{cm}^{-3}\right)\end{array}$ & $\begin{array}{c}b \\
\left(\operatorname{bar}^{-1}\right)\end{array}$ & $\begin{array}{c}C_{\mathrm{H}}^{\prime} b \\
\left(\mathrm{~cm}^{3}(\mathrm{STP}) \mathrm{cm}^{-3} \mathrm{bar}^{-1}\right)\end{array}$ & $\begin{array}{c}\mathrm{AAD} \\
(\%)\end{array}$ \\
\hline Annealed PLA 98:2 & $\begin{array}{l}303.9 \\
313.8 \\
323.8\end{array}$ & $\begin{array}{l}2.57 \\
2.12 \\
1.78\end{array}$ & $\begin{array}{l}9.16 \\
7.90 \\
5.79\end{array}$ & $\begin{array}{l}0.26 \\
0.25 \\
0.11\end{array}$ & $\begin{array}{l}2.36 \\
1.96 \\
0.62\end{array}$ & $\begin{array}{l}2.0 \\
1.4 \\
1.6\end{array}$ \\
\hline Melted PLA 98:2 & $\begin{array}{l}303.5 \\
313.5 \\
323.4\end{array}$ & $\begin{array}{l}2.08 \\
1.53 \\
1.25\end{array}$ & $\begin{array}{l}9.00 \\
6.20 \\
4.87\end{array}$ & $\begin{array}{l}0.28 \\
0.17 \\
0.04\end{array}$ & $\begin{array}{l}2.51 \\
1.08 \\
0.19\end{array}$ & $\begin{array}{l}2.7 \\
3.1 \\
2.2\end{array}$ \\
\hline Quenched PLA 98:2 & $\begin{array}{l}304.6 \\
313.5 \\
323.4\end{array}$ & $\begin{array}{l}2.05 \\
1.70 \\
1.35\end{array}$ & $\begin{array}{l}8.69 \\
6.50 \\
5.50\end{array}$ & $\begin{array}{l}0.30 \\
0.18 \\
0.07\end{array}$ & $\begin{array}{l}2.61 \\
1.17 \\
0.39\end{array}$ & $\begin{array}{l}2.3 \\
3.8 \\
2.7\end{array}$ \\
\hline Annealed PLA 80:20 & $\begin{array}{l}303.9 \\
313.9 \\
323.7\end{array}$ & $\begin{array}{l}2.44 \\
1.99 \\
1.55\end{array}$ & $\begin{array}{l}1.80 \\
1.60 \\
1.39\end{array}$ & $\begin{array}{l}0.06 \\
0.01 \\
0.001\end{array}$ & $\begin{array}{l}0.11 \\
0.02 \\
0.001\end{array}$ & $\begin{array}{l}7.4 \\
6.2 \\
4.6\end{array}$ \\
\hline Melted PLA 80:20 & $\begin{array}{l}303.7 \\
313.7 \\
323.5\end{array}$ & $\begin{array}{l}2.76 \\
2.12 \\
1.71\end{array}$ & $\begin{array}{l}9.00 \\
7.01 \\
4.95\end{array}$ & $\begin{array}{l}0.01 \\
0.002 \\
0.0001\end{array}$ & $\begin{array}{l}0.08 \\
0.01 \\
0.0005\end{array}$ & $\begin{array}{l}6.0 \\
7.4 \\
7.4\end{array}$ \\
\hline Quenched PLA 80:20 & $\begin{array}{l}305.2 \\
313.9 \\
323.7\end{array}$ & $\begin{array}{l}2.30 \\
1.90 \\
1.63\end{array}$ & $\begin{array}{l}9.23 \\
6.00 \\
4.38\end{array}$ & $\begin{array}{l}0.004 \\
0.001 \\
0.001\end{array}$ & $\begin{array}{l}0.04 \\
0.01 \\
0.002\end{array}$ & $\begin{array}{l}6.7 \\
6.2 \\
6.2\end{array}$ \\
\hline
\end{tabular}

results, with an overall $\mathrm{AAD}$ of $6.1,6.9$, and $6.4 \%$ for the annealed, melted, and quenched PLA 80:20. Sensitivity analysis of the three parameters of the DMSM clearly indicates the coupling of $C_{\mathrm{H}}^{\prime}$ and $b$ terms. So $C_{\mathrm{H}}^{\prime} b$ product, which is often called the apparent Langmuir capacity, is also reported in Table 3 . The analysis of the DMSM parameters for $\mathrm{CO}_{2}$ in PLA 98:2 and 80:20 leads to the conclusion that in general the solubility for all the three types of thermal treatment is governed by a Henry type of sorption, since the magnitude of $k_{\mathrm{D}}$ is higher than $C_{\mathrm{H}}^{\prime} b$. However, the apparent Langmuir capacity is very large in PLA 98:2 while in PLA 80:20 it is almost negligible. This is probably due to a more complex structure that is formed when crystallites are present, creating a larger free volume. Also, the apparent Langmuir capacity diminishes as temperature approaches the glass transition temperature. This observation is consistent with the fact that the Langmuir capacity is directly related to the effective free volume that tends to zero at $T_{\mathrm{g}}$. These results show that the different content of $L: D$ isomers in PLA does influence not only the magnitude of the solubility but also its mechanism.

The Flory-Huggins equation was also used to fit the experimental results and the adjustable binary interaction parameters for each system and the respective AAD's are presented in Table 4 for all the studied systems. From the deviations it can clearly be concluded that this model does not present any advantage for the systems

Table 4. Adjustable Binary Interaction Parameters for Flory-Huggins Equation Fitted to Experimental Solubility Results

\begin{tabular}{lccc}
\hline & $T(\mathrm{~K})$ & $\chi_{12}$ & $\mathrm{AAD}(\%)$ \\
\hline \multirow{2}{*}{ Annealed PLA 98:2 } & 303.9 & 0.06 & 31.1 \\
& 313.8 & 0 & 25.7 \\
Melted PLA 98:2 & 323.8 & -0.01 & 18.5 \\
& 303.5 & 0.38 & 45.9 \\
& 313.5 & 0.37 & 31.6 \\
Quenched PLA 98:2 & 323.4 & 0.36 & 17.9 \\
& 304.6 & 0.22 & 37.7 \\
Annealed PLA 80:20 & 313.5 & 0.21 & 30.5 \\
& 323.4 & 0.20 & 26.6 \\
Melted PLA 80:20 & 313.9 & 0.16 & 14.5 \\
& 323.7 & 0.14 & 8.7 \\
& 303.7 & 0.02 & 5.8 \\
Quenched PLA 80:20 & 313.7 & 0.02 & 4.6 \\
& 323.5 & 0.02 & 5.6 \\
& 305.2 & 0.14 & 13.4 \\
& 313.9 & 0.12 & 7.8 \\
& 323.7 & 0.10 & 4.2 \\
\hline
\end{tabular}

Journal of Polymer Science: Part B: Polymer Physics 

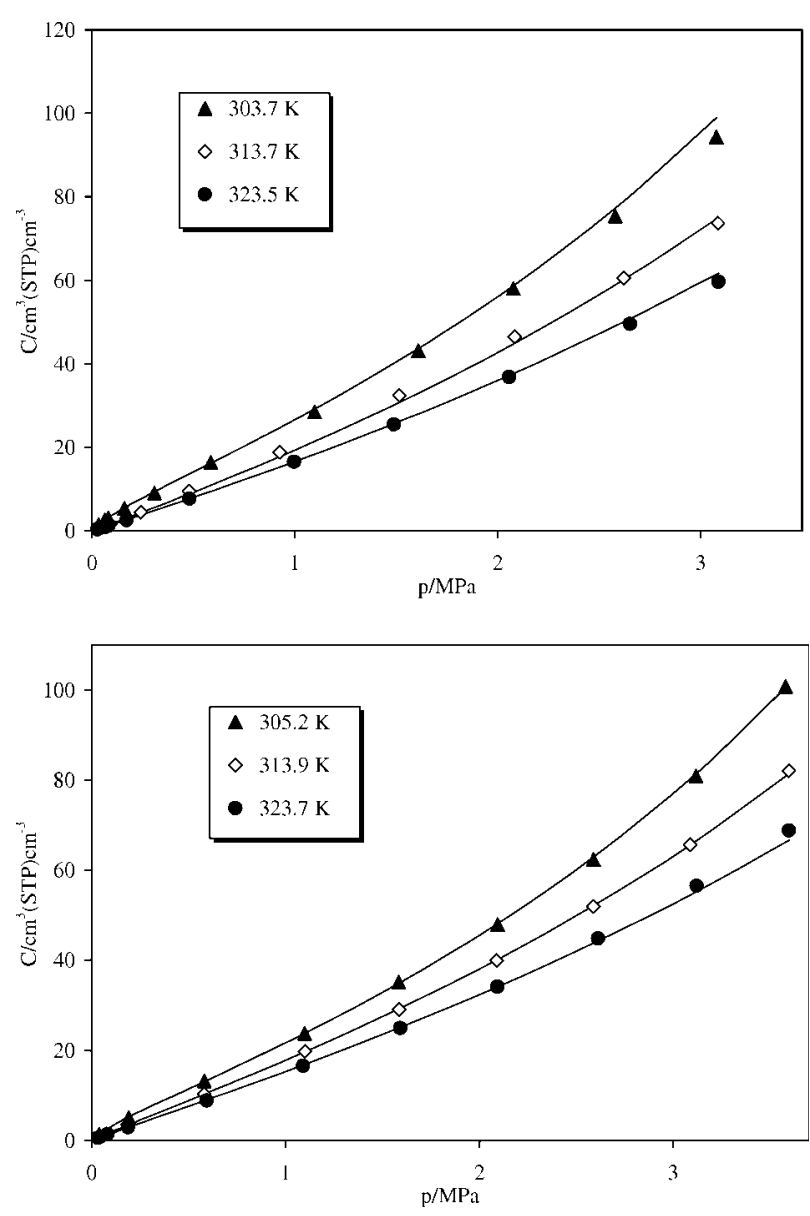

Figure 4. Solubility results of carbon dioxide in PLA 80:20 (a) melted and (b) quenched. Solid lines are calculated using Flory-Huggins/Langmuir DMSM.

involving PLA 98:2. On the contrary, the FloryHuggins equation provides the correct pressure dependence for the PLA 80:20 systems, especially the pronounced upward curvature found for these systems.

The most usual model used to fit experimental solubilities of gases in glassy polymers is DMSM. Although it correlates accurately the carbon dioxide solubility in PLA 98:2 for all the three thermal treatments, it provides a very poor description of the systems involving PLA 80:20, due to the convex upward curvature relative to the pressure axes for pressure higher than $2 \mathrm{MPa}$. On the other hand, the Flory-Huggins model performs exactly in the opposite way, correlating satisfactorily the PLA 80:20 systems but yielding large deviations for the PLA 98:2 systems. Keeping in mind that in the DMSM, the Langmuir isotherm is important at low

Journal of Polymer Science: Part B: Polymer Physics DOI 10.1002/polb pressures and Henry's law is dominant at higher pressures, if the Henry's law is replaced by Flory-Huggins equation, a better correlation of our experimental results can be expected. In Figures $4(a, b)$ and $5(a, b)$, it can be seen that this model describes well solubility of $\mathrm{CO}_{2}$ in both PLA 80:20 and PLA 98:2, with overall AAD of 2.2 and $4.0 \%$, respectively. The adjustable parameters of this model for the studied systems as well as the AAD's are presented in Table 5.

\section{CONCLUSIONS}

The solubility of carbon dioxide in PLA 80:20 and 98:2 was measured between 303 and $323 \mathrm{~K}$ and pressures up to $5 \mathrm{MPa}$ with a high pressure QCM. Two thermal treatments were performed in both PLA 80:20 and PLA 98:2 and the
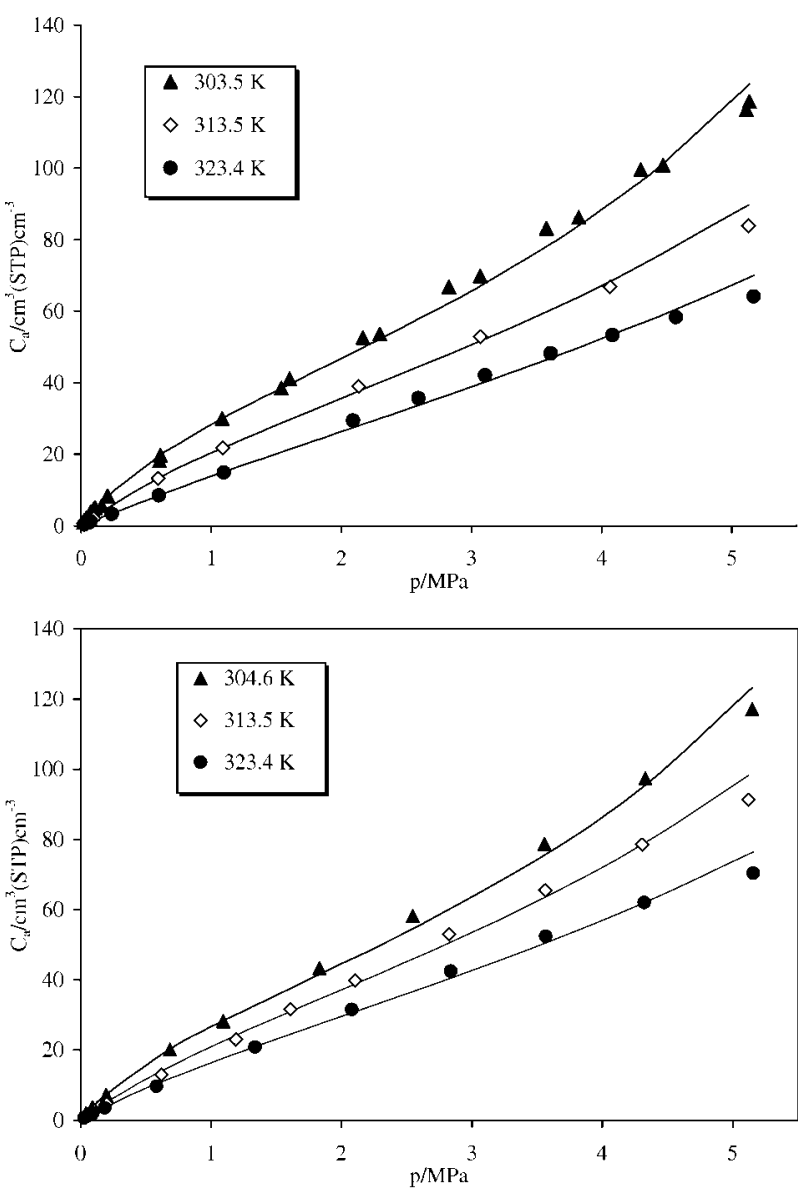

Figure 5. Solubility results of carbon dioxide in PLA 98:2 (a) melted and (b) quenched. Solid lines are calculated using Flory-Huggins/Langmuir DMSM. 
Table 5. Adjustable Model Parameters for Flory-Huggins Equation with Langmuir Isotherm

\begin{tabular}{|c|c|c|c|c|c|}
\hline & $T(\mathrm{~K})$ & $\chi$ & $C_{\mathrm{H}}^{\prime}\left(\mathrm{cm}^{3}(\mathrm{STP}) \mathrm{cm}^{-3}\right)$ & $b\left(\mathrm{bar}^{-1}\right)$ & $\mathrm{AAD}(\%)$ \\
\hline Annealed PLA 98:2 & $\begin{array}{l}303.9 \\
313.8 \\
323.8\end{array}$ & $\begin{array}{l}0.66 \\
0.62 \\
0.58\end{array}$ & $\begin{array}{l}54.91 \\
48.42 \\
56.71\end{array}$ & $\begin{array}{l}0.06 \\
0.06 \\
0.03\end{array}$ & $\begin{array}{l}2.9 \\
3.2 \\
1.1\end{array}$ \\
\hline Melted PLA 98:2 & $\begin{array}{l}303.5 \\
313.5 \\
323.4\end{array}$ & $\begin{array}{l}0.79 \\
0.77 \\
0.75\end{array}$ & $\begin{array}{l}31.14 \\
28.93 \\
26.00\end{array}$ & $\begin{array}{l}0.12 \\
0.06 \\
0.03\end{array}$ & $\begin{array}{l}6.8 \\
5.6 \\
4.1\end{array}$ \\
\hline Quenched PLA 98:2 & $\begin{array}{l}304.6 \\
313.5 \\
323.4\end{array}$ & $\begin{array}{l}0.71 \\
0.67 \\
0.65\end{array}$ & $\begin{array}{l}28.43 \\
26.32 \\
19.33\end{array}$ & $\begin{array}{l}0.12 \\
0.07 \\
0.07\end{array}$ & $\begin{array}{l}3.3 \\
5.3 \\
3.8\end{array}$ \\
\hline Annealed PLA 80:20 & $\begin{array}{l}303.9 \\
313.9 \\
323.7\end{array}$ & $\begin{array}{l}0.30 \\
0.26 \\
0.21\end{array}$ & $\begin{array}{l}7.14 \\
3.89 \\
3.08\end{array}$ & $\begin{array}{l}0.35 \\
0.23 \\
0.10\end{array}$ & $\begin{array}{l}1.6 \\
1.3 \\
0.4\end{array}$ \\
\hline Melted PLA 80:20 & $\begin{array}{l}303.7 \\
313.7 \\
323.5\end{array}$ & $\begin{array}{l}0.09 \\
0.04 \\
0.01\end{array}$ & $\begin{array}{l}4.38 \\
2.96 \\
2.22\end{array}$ & $\begin{array}{l}0.63 \\
0.01 \\
0.00\end{array}$ & $\begin{array}{l}2.5 \\
4.7 \\
6.3\end{array}$ \\
\hline Quenched PLA 80:20 & $\begin{array}{l}305.2 \\
313.9 \\
323.7\end{array}$ & $\begin{array}{l}0.20 \\
0.18 \\
0.15\end{array}$ & $\begin{array}{l}3.12 \\
1.95 \\
1.68\end{array}$ & $\begin{array}{l}0.94 \\
0.25 \\
0.16\end{array}$ & $\begin{array}{l}0.9 \\
0.8 \\
1.5\end{array}$ \\
\hline
\end{tabular}

solubility results were compared. From the experimental results, it can be concluded that, for pressures higher than $2 \mathrm{MPa}$, the carbon dioxide solubility is larger in PLA 80:20 than in PLA 98:2, indicating that the $L: D$ plays a dominant role on this property. Also worthwhile noticing is the fact that only one thermal treatment, annealing, affects the gas solubility in PLA 98:2. It can also be observed that PLA 80:20 swells at the studied temperature and pressure conditions while PLA 98:2 does not swell, probably due to the presence of crystallites.

It can also be concluded from the application of the DMSM that in general the solubility of CO2 in both PLA 98:2 and 80:20 is determined by the a Henry type of sorption. However, it was also found that the apparent Langmuir capacity is much larger in PLA 98:2 than in PLA 80:20, where it is almost negligible. The model combining the Flory-Huggins model and the Langmuir isotherm proved to be very versatile in correlating both polymer systems with and without swelling and presenting the lowest deviations from the three studied models.

This project was financed by Fundação para a Ciência e Tecnologia, POCTI/EQU/43,356/2001. N. S. Oliveira thanks Fundação para a Ciência e a Tecnologia the Ph.D. scholarship (SFRH/BD/6690/2001).

\section{REFERENCES AND NOTES}

1. Wang, N.-H.; Takishima, S.; Masuoka, H. Int Chem Eng 1994, 34, 255.

2. Miura, K-I.; Otake, K.; Kurosawa, S.; Sako, T.; Sugeta, T.; Nakane, T.; Sato, M.; Tsuji, T.; Hiaki, T.; Hongo, M. Fluid Phase Equilib 1998, 144, 181.

3. Aubert, J. H. J Supercrit Fluids 1998, 11, 163.

4. Boudouris, D.; Prinos, J.; Bridakis, M.; Pantoula, M.; Panayiotou, C. Ind Eng Chem Res 2001, 40, 604.

5. Zhang, C.; Cappleman, B. P.; Defibaugh-Chavez, M.; Weinkauf, D. H. J. Polym Sci Part B: Polym Phys 2003, 41, 2109.

6. Zhang, C.; Wyatt, J.; Russel, S. P.; Weinkauf, D. H. Polymer 2004, 45, 7655.

7. Zhang, C.; Wyatt, J.; Weinkauf, D. H. Polymer 2004, 45, 7665 .

8. Bonner, D. C.; Cheng, Y. J. Polym Sci Polym Lett Ed 1975, 13, 259.

9. McDowell, C. C. Ph.D. Thesis, North Carolina State University, Raleigh, NC, 1998.

10. Andrade, G. S.; Collard, D. M.; Schiraldi, D. A.; $\mathrm{Hu}$, Y.; Baer, E.; Hiltner, A. J Appl Polym Sci 2003, 89, 934.

11. Liu, R. Y. F.; Hiltner, A.; Baer, E. J Polym Sci Part B: Polym Phys 2004, 42, 493.

12. Tsujita, Y. Prog Polym Sci 2003, 28, 1377.

13. Russell, S. P.; Weinkauf, D. H. Polymer 2001, 42 , 2827.

Journal of Polymer Science: Part B: Polymer Physics 
14. Oliveira, N. S.; Dorgan, J.; Coutinho, J. A. P.; Ferreira, A.; Daridon, J. L.; Marrucho, I. M. J Polym Sci Part B: Polym Phys 2006, 44, 1010.

15. Kanehashi, S.; Nagai, K. J Membr Sci 2005, 253, 117.

16. Flory, P. J. In Principles of Polymer Chemistry; Cornell University Press: Ithaca, NY, 1953; Chapter 12 , pp 495-540.

17. Prausnitz, J. M.; Lichtenthaler, R. N.; Gomes de Azevedo, E. Molecular Thermodynamics of FluidPhase Equilibria; Prentice Hall PTR: Upper Saddle River, NJ, 1999.

18. Wong, H. C.; Campbell, S. W.; Bhethanabotla, V. R. Fluid Phase Equilib 2001, 179, 181.

19. Birdi, K. S., Ed. In Handbook of Colloid and Surface Chemistry, 2nd ed.; CRC Press: Boca Raton, FL, 2002.
20. Ely, J. F. NIST Mixture Property Program (DDMIX); National Institute of Standard and Technology: Gaithersburg, MD, 1990.

21. Hernandez, R. J.; Giacin, J. R.; Grulke, E. A. J Membr Sci 1992, 65, 187.

22. Hernandez, R. J.; Gavara, R. J Polym Sci Part B: Polym Phys 1994, 32, 2367.

23. Seregin, A. V.; BondaR', V. I.; Mattes, B. R. Yampol'skii, Y. P.; Volkov, V. V. Polym Sci Ser B 1996, 38, 165.

24. Lechermeier, H. J.; Dorgan, J. R.; Way, J. D. J Membr Sci 2001, 190, 243.

25. Auras, R.; Harte, B.; Selke, S. Macromol Biosci 2004, 4, 835 .

26. Oliveira, N. S.; Oliveira, J.; Gomes, T.; Ferreira, A.; Dorgan, J.; Marrucho, I. M. Fluid Phase Equilib 2004, 222/223, 317. 